\title{
Effect of Oatmeal Oil on Hair Texture Improvement
}

Ju-Sub Kim

Department of Beauty Design, Sangji University, Wonju-si, Gangwon-do, Korea

Corresponding author: Ju-Sub Kim, Department of Beauty Design, Sangji University, 84 Sangjidae-gil, Wonju-si, Gangwon-do 26339, Korea

Tel.: +82 337300811

Fax: +82337300811

Email: c-miro@hanmail.net

Received August 27, 2020

Revised October 15, 2020

Accepted October 30, 2020

Published December 30, 2020

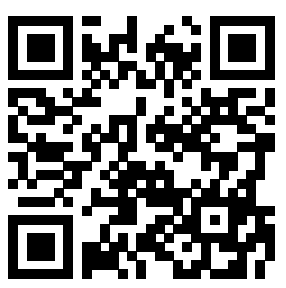

\begin{abstract}
Purpose: The current study aimed to assess the effects of oatmeal oil on improving hair texture. Hence, an agent with oatmeal oil was developed, and it was applied to damaged hair. Methods: The hair texture improvement agent was produced with different amounts of oatmeal oil $(0,1,2$, and $3 \mathrm{~g})$. After applying the agent to bleached hair, it was heat-treated and left in natural condition. The experimental and control groups were assessed and compared. Results: The $\mathrm{L}^{*}$ value was higher in the experimental group than in the control group. The $a^{*}$ value was higher in the experimental group than in the control group. The $b^{*}$ value was higher in the experimental group than in the control group. Fading as much as 16.68 NTU was observed on day 1 , but not on day 4 . The hair tensile strength was lower in the experimental group than in the control group. In level 7, the tensile strength increased with a higher amount of oatmeal oil. Further, the gloss value was higher in the experimental group than in the control group. However, in level 7 , the gloss value did not significantly decrease with a higher content of oatmeal oil. Conclusions: This study showed the effects of oatmeal oil on improving the texture of damaged hair. However, further studies on the effects of oatmeal oil on improving hair texture and continuity based on the oil ingredient should be conducted in the future.
\end{abstract}

Keywords: Oatmeal oil, Hair, Improvement, Hair texture, Damage

\section{Introduction}

검고 아름다운 머리 결을 유지 관리하는 것은 건강한 아름다움을 추구하는 중요한 내용이다. 신체의 아름다움에는 외모, 몸매가 중요 하지만 머리 결의 건강 역시 아름다움을 표현하는데 중요한 요소이 다. 모발의 건강 함은 신체의 건강함을 체크하는 척도이기도 하다. 이러한 검고 생머리의 건강함을 추구하고 있으나 미용 산업과 미용 디자인적 테크닉의 발달하면서 아름다움의 기준이 검은 모발 뿐만 아니라 다양한 컬러 염색으로 인한 화려한 헤어 컬러, 생머리에 디 자인적 요소를 더한 웨이브에 의한 헤어 디자인적 아름다움을 추구 하고 있다. 이러한 아름다운 헤어 디자인에 만족하고 있는 반면에 염색제에 의한 헤어 컬러로 인해 결합력이 약화되며 멜라닌 색소가 파괴되고, 퍼머제에 의한 웨이브로 인해 시스틴 결합력이 약해지는 등 모발 자체의 건강 함은 점차 잃어가고 있다. 모발은 한번 손상되 면 재생능력이 없어 다시 건강한 모발로 회복 될 수가 없다(Kim et al., 2010). 손상된 모발을 건강모에 가깝게 개선하기 위해 많은 노 력과 연구가 이루어지고 있다. 화학 제품 자체적으로 손상을 줄이는
방법으로 퍼머넌트웨이브시 water wrapping 시술이 웨이브 효율성 에 미치는 영향(Choi \& Park, 2010), 화학적 처리 후 모질의 개선 방법으로 해양심층수로 모발 처리 시 형태학적 및 화학적 변화(Choi $\&$ Lee, 2015), 손상된 모발을 완화 시켜주는 성분에 대한 연구로 천 연추출물의 손상모발 개선 효과에 관한 연구(Kim \& Han, 2013) 등 이 활발히 이루어지고 있다. 처리방법, 성분에 의한 연구는 활발히 이루어지고 있으나 아직도 분야별로 미비한 부분이 있다. 이에 모발 개선 분야 중 성분에 의한 개선 효과 방법으로 천연 성분 오일을 이 용한 연구를 하고자 한다. 모질 개선에서 천연 성분에 의한 연구로 는 아로마 오일을 이용한 두피수기요법이 두피와 모발 상태에 미치 는 영향(Park \& Lee, 2012), 모발 및 피부 개선의 오존화 올리브 오 리 생산에 대한 안전성에 과한연구(Park, 2015), 녹차씨 오일이 염 색 및 탈색된 모발의 재손상 및 탈색 방지에 미치는 양향(Min et al., 2013) 등이 있다. 이러한 천연 성분 중 오트밀 오일로 모질 개선 효 과를 알아보고자 한다. 오트밀은 서유럽에서 많이 경작되고 있는 작 물로 생산량의 $95 \%$ 가 사료로 이용되고 있고, 나머지가 식량으로 사 용되고 있으며 단백질 함량이 많고 식이섬유가 풍부하다(Hwang et 
al., 2020). 오트밀에 과한 선행 연구로는 대체 감미료를 첨가한 오 트밀 쿠티의 품질 특성 및 혈당에 미치는 영향(Bang et al., 2013), 귀리 분말을 첨가한 된장의 맛 성분과 품질 특성(Kim et al., 2016).

귀리 및 쌀귀리 분말의 입자 크기별 영양성분 및 이화학적 특성 (Lee et al., 2016) 등의 연구가 이루어 졌다. 주로 식품과 관련된 연 구가 많고 헤어, 모발과 관련된 연구는 미비한 실정이다. 이에 귀리 의 오트밀 오일로 모질의 개선 정도를 알아보고자 하였다.

따라서 본 연구는 오트밀 오일이 모질 개선 원료로 사용 가능 한 가를 알아보고자 하였다. 실험을 위해 오트밀 오일을 함량 별로 다 르게 첨가하여 사용하였다. 도포 시 모발에 오일의 흡착력을 높이기 위해 펌베이스제에 함량을 다르게 첨가하여 제조하였다. 제조된 제 형으로 모발에 도포하여 대조군과 실험군으로 분류하여 비교 분석 하였다. 비교 분석은 오트밀 오일에 의해 모발의 색이 변화 하는지 를 알아보고자 색차계 측정과 물 빠짐을 측정하였고, 손상된 모발을 개선하는데 효과가 있는지 알기 위해 인장강도, 메틸렌블루를 이용 한 흡광도 측정, 광택을 측정하여 모질 개선 정도를 알아보고자 하 였다.

\section{Methods}

\section{1. 실험재료}

1) 시료 모발

연구에 사용된 시료 모발은 최근 2 년 동안 약물복용과 화학적 시술을 하지 않은 18 세 여성의 모발을 후두부에서 두피 $3 \mathrm{~cm}$ 지 점을 기준으로 $20 \mathrm{~cm}$ 로 채취하여 $2 \mathrm{~g}$ 씩 모(hair) 다발을 만들었 다. 플레인 린스 후 자연건조하여 사용하였다. 오트밀 오일의 모 발 손상 개선 정도를 연구하기 위하여 화학적시술을 전혀 하지 않 은 건강모와 건강 모발에 탈색제 제1제(ammonium persulfate, potassium persulfate, sodium metasilicate, magnesium, sodium carboxymethyl cellulose) (Suanhj, Korea) $3 \mathrm{mg}$ 과 제2제(6\%의 과 산화수소를 주성분으로 water, etidronic acid, phosphoric acid, sodium phosphate dibasic, cetyl alcohol로 구성된 제품) (Suanhj, Korea) $3 \mathrm{~mL}$ 비율로 혼합, 도포하고 $30 \mathrm{~min}$ 방치 후 세척하여 명도 7 레벨 시료 4 다발과 명도 차에 의한 비교를 위해 한번의 탈색을 더 해서 9 레벨의 시료 1 다발을 제작하였다. 실험에 사용된 모발 시료의 level 측정기(level scale, Wella, Germany) 사용하였으며 level 측정 은 미용 전문가 미용 경력이 5 년이상인 2 인이 측정하였다. 이 시료 에 오트밀 오일로 제조된 제형제를 이용하여 모발 시료에 도포 후를 함량 별에 따른 비교 분석을 하였다.

\section{2) 오트밀 오일}

실험에 사용 한 오트밀 오일은 원산지는 영국이고 추출은 씨에 서 추출한 오일로 화장품원료로 사용되는 오일(Korea Similac, Walterenterprise Co., Lt, Korea)을 구입하여 사용하였다.

\section{3) 모질 개선 제형제 제조}

실험에 사용한 모질 개선 제형제의 펌베이스제는 (주)수안향장 (Korea)에서 제조한 것으로 모든 제조에 사용하였으며, 펌베이스제 조성표는 Table 1과 같다. 이 펌베이스제에 오트밀 오일 $0 \mathrm{~g}, 1 \mathrm{~g}, 2 \mathrm{~g}$, $3 \mathrm{~g}$ 을 함량을 다르게 하여 혼합 제조였다.

\section{4) 측정기기 및 측정방법}

(1) 도포 전·후의 표면 색상 $\left(\mathrm{L}^{*}, \mathrm{a}^{*}, \mathrm{~b}^{*}\right)$ 변화 측정

함량 별로 오트밀 오일이 함유된 모발 개선 제형제로 도포 전과 후의 표면 색상 변화를 알아보고자 색차계(Color meter, CS-10; $\mathrm{CHN}$ spec, China)를 이용하여 CIELAB 표색계의 색상 값인 명도 지수 $\mathrm{L}^{*}$ 과 색 좌표 지수인 $\mathrm{a}^{*}$ 와 $\mathrm{b}^{*}$ 값을 측정하였다.

$\mathrm{L}^{*}$ : CIELAB 표색계의 white-black축에서의 명도지수

$a^{*}$ : CIELAB 표색계의 red-green 축에서의 채도지수

\section{Table 1. Composition of perm-base agent}

\begin{tabular}{llcc}
\hline No & Ingredients & Content (\%) & Function \\
1 & Water & 89.850 & Solvent \\
2 & Tri ethanolamine & 0.150 & pH adjuster \\
3 & Cetyl alcohol & & Emulsion stabilizer \\
& Ceteth-40 & 3.000 & Surfactant \\
& Myristyl alcohol & & Emulsion stabilizer \\
& Cetyl alcohol & & Emulsion stabilizer \\
4 & Stearyl alcohol & & Emulsion stabilizer \\
& Arachidyl alcohol & 2.000 & Emulsion stabilizer \\
& Stearic acid & & Surfactant \\
& Palmitic acid & & Surfactant \\
& Myristic acid & & Surfactant \\
\end{tabular}


$\mathrm{b}^{*}$ : CIELAB 표색계의 yellow-blue 축에서의 채도지수

측정값의 신뢰성을 높이기 위해 5 번 측정하여 최고 값과 최저 값 을 제외한 나머지 값의 평균을 구하였다.

\section{(2) 물 빠짐 측정}

오트밀 오일로 제조된 제형제의 물 빠짐 정도를 알기 위함이다. 물 빠짐 측정 방법은 탁도계(Turbidity meter, TU-2016; Lutron electronic, Taiwan) 기기를 이용하여 시료 별 측정하였다. $100 \mathrm{~mL}$ 비이커에 정제수를 넣고 시료를 담근 후 $24 \mathrm{~h}$ 후에 탁도를 측정하였 다. 측정 기간은 물 빠짐이 없을 때까지 $24 \mathrm{~h}$ 주기로 측정하였다.

물 빠짐 측정을 위해서는 모든 시료를 사용하지는 않고, 가장 명 도가 높은 9 레벨의 시료로 물 빠짐 측정을 하였다.

\section{(3) 인장강도 측정}

모질의 개선 정도를 알기 위해 함량 별 제형제로 모발 시료에 도 포 후의 인장강도를 각시료 별로 측정하였다. 측정 기기(Digital force gauge, HF-20; Tripod, China)로 인장강도를 측정하였다. 측정값의 신뢰성을 위하여 5 회 측정 후 측정 값 중 최고값과 최저값 을 제외한 나머지 측정값의 평균값을 구하였다.

\section{(4) 메틸렌블루를 이용한 흡광도 측정}

모질의 손상 개선 정도를 알기 위해 함량 별로 오트밀 오일을 함 유한 개선 제형제로 모발 시료에 도포 후 흡광도를 측정하였다. 모발의 외경은 마이크로미터(Quickmike, Mitutoyo)를 이용하여 0.07-0.08 mm의 굵기 오차범위를 정하고 $5 \mathrm{~cm}$ 의 길이로 3 가닥 잘랐다. 자른 후 3 가닥의 모발을 tube에 넣은 후 $\mathrm{MB}$ solution에 담 가 vortex mixer (Vortex genie 2, Scientific Industries, USA)를 이용하여 $10 \mathrm{~s}$ 동안 vortexing하였다. $50^{\circ} \mathrm{C}$ heat block (wise therm $\mathrm{HB}-48 \mathrm{P}$; Daihan Scientific, Korea)에서 $10 \mathrm{~min}$ 간 유지하여 $\mathrm{MB}$ solution을 흡착시키고, tube에 있는 3 가닥의 시료를 꺼내어 표면에 묻어있는 MB solution은 실험용 티슈를 이용하여 제거하고, 시료 3 가닥을 각각 새 tube에 옮겨 담았다. 이 tube에 NR desorb solution 을 $5 \mathrm{~mL}$ 를 넣고 상온에서 $5 \mathrm{~min}$ 방치 후 $10 \mathrm{~s}$ vortexing 후 추출하 였다. 추출한 용액을 큐벳(cuvettes)에 $3000 \mu \mathrm{L}$ 분주하여 $\mathrm{MB}$ 의 흡 수 강도가 가장 높은 파장인 $660 \mathrm{~nm}$ 로 흡광도를 측정하였다. 1회
추출 후 같은 방법으로 총3회 분광광도계(Vis spectrophotometer, SV1200; Azzota, USA)로 흡광도를 측정하고 그 값의 평균을 구하 였다. 측정 시 기준 값을 잡기 위해 desorb solution을 $3000 \mu \mathrm{L}$ 분주 하여 blank를 만들어준다. $\mathrm{MB}$ 시약은 DW $20 \mathrm{~mL}+\mathrm{MB} 400 \mu \mathrm{L}$ 으 로 희석하여 $2 \%$ 로 만들어 사용하였다. NR solution은 $49 \%$ ethanol $(49 \mathrm{~mL})+1 \%$ glacial aceticacid $(1 \mathrm{~mL})+50 \% \mathrm{DW}(50 \mathrm{~mL})$ 의 비 율로 희석하여 사용하였다.

(5) 모발 표면 광택 측정

모질의 손상 개선 정도를 알기 위함이다. 함량 별로 오트밀 오 일을 함유한 개선 제형제로 모발 시료에 도포 후의 광택 변화를 알아보고자 광택계(Gloss meter NHG268; Shenzhen Threenh Technology, China)를 이용하여 측정하였다. 측정값의 신뢰성을 높 이기 위해 5 번 측정하여 최고 값과 최저 값을 제외한 나머지 값의 평 균을 구하였다.

\section{5) 도포 실험방법}

건강모와 탈색으로 시술 한 모발 시료 7레벨, 9레벨 시료에 오트 밀 오일을 $0 \mathrm{~g}, 1 \mathrm{~g}, 2 \mathrm{~g}, 3 \mathrm{~g}$ 함량을 첨가한 모질 개선 제형제를 $20 \mathrm{~g}$ 제조하여 각각의 시료에 $15 \mathrm{~g}$ 도포하였다. 도포한 후 열처리 $10 \mathrm{~min}$ 과 자연건조 $20 \mathrm{~min}$ 후에 세척하여 자연건조 시켜 측정하였다. 모질 개선 제형제 도포는 도포량, 자연방치시간, 열처리 시간, 시술자의 숙련도에 등에 따라서 측정에 차이가 있을 수 있기 때문에 최대한 차 이를 줄이기 위해 시술자는 각 단계별로 동일인이 시술하였다. 대조 군은 건강모와, 오트밀 오일 $0 \mathrm{~g}$ 을 도포한 시료로 하고, 실험군은 오 트밀 오일 $1 \mathrm{~g}, 2 \mathrm{~g}, 3 \mathrm{~g}$ 을 도포한 시료로 하였다. 각 오트밀 오일의 함량에 따른 모질 개선 제형제 시료 표기는 Table 2 와 같다.

\section{6) 분석 방법}

각 항목의 실험은 실험에 따라 표면색변화, 인장강도, 광택측정 은 5 회 측정 후 최고값과 최저값을 제외 한 3 회의 값의 평균으로 분 석하고, 흡광도는 3 회 실시한 값의 평균 값으로 도포 전과 후의 값을 비교하였다. 물빠짐 측정은 $24 \mathrm{~h}$ 주기로 물빠짐이 없을때까지의 탁 도를 측정하였다.

Table 2. Expression method for samples

\begin{tabular}{ll}
\hline Sample & Undamaged hair \\
\hline Virgin hair & Treatment of level-7 sample with oatmeal oil $0 \mathrm{~g}$ and perm-base $20 \mathrm{~g}$ \\
7 level $(0 \mathrm{~g})$ & Treatment of level-7 sample with oatmeal oil $1 \mathrm{~g}$ and perm-base $19 \mathrm{~g}$ \\
7 level $(1 \mathrm{~g})$ & Treatment of level-7 sample with oatmeal oil $2 \mathrm{~g}$ and perm-base $18 \mathrm{~g}$ \\
7 level $(2 \mathrm{~g})$ & Treatment of level-7 sample with oatmeal oil $3 \mathrm{~g}$ and perm-base $17 \mathrm{~g}$ \\
7 level $(3 \mathrm{~g})$ & Treatment of level-9 sample with oatmeal oil $3 \mathrm{~g}$ and perm-base $17 \mathrm{~g}$ \\
\hline
\end{tabular}




\section{Results and Discussion}

\section{1. 오트밀 오일 함량에 따른 도포 전, 후의 표면 색상 변화 측정}

모발 손상을 줄이기 위한 방법으로 천연 염모제의 연구 개발이 꾸 준히 이루어지고 있다. 천연 성분인 오트밀 오일 함량을 $0 \mathrm{~g}, 1 \mathrm{~g}$, $2 \mathrm{~g}, 3 \mathrm{~g}$ 으로 다르게 하여 펌베이스에 혼합 제조한 모질 개선 제형 제로 시료 별 도포 후의 모발 표면 색상 변화를 측정 한 결과 다음과 같은 결과를 얻을 수 있었다.

\section{1) 시료 별 $L^{*}$ 측정}

오트밀 오일을 $0 \mathrm{~g}, 1 \mathrm{~g}, 2 \mathrm{~g}, 3 \mathrm{~g}$ 함량 별로 제조한 모질 개선 제 형제로 도포한 후 열처리 $10 \mathrm{~min}$ 과 자연방치 $20 \mathrm{~min}$ 후에 모발의 표면 색상 측정 결과 $\mathrm{L}^{*}$ 값은 Table 3 과 같다.

$\mathrm{L}^{*}$ 은 밝기인 명도(lightness)를 표현하는 수치로 0에서 100사이 의 수치로 표시한다. 오트밀 오일을 함유한 개선 제형제로 도포한 후의 대조군과 실험군의 $\mathrm{L}^{*}$ 값 결과는 대조군 인 건강모보다는 실험 군 모두가 높은 것으로 나타났다. 이는 탈색에 의한 멜라닌 색소의 파괴로 모발의 색상을 밝게 한 경우이다(Kang, 2015)의 내용과 같 은 것으로 명도가 높아진 결과이다. 대조군 인 $0 \mathrm{~g}$ 함유한 것보다 실 험군 7레벨에서 $1 \mathrm{~g}, 2 \mathrm{~g}, 3 \mathrm{~g}$ 함유한 시료의 L값은 오트밀 함량이 높을수록 감소함을 알 수 있었다. 이는 오트밀 오일이 모발 표면 등 에 흡착이 된 결과로 사료된다. 7레벨에서 $2 \mathrm{~g}$ 과 $3 \mathrm{~g}$ 의 $\mathrm{L}^{*}$ 값 차이는 1.33 로 큰 차이는 없는 것을 알 수 있었다. 오트밀 오일 $3 \mathrm{~g}$ 을 도포 한 7레벨과 9 레벨의 실험군의 $\mathrm{L}^{*}$ 값 차이는 9 레벨의 $\mathrm{L}^{*}$ 값이 26.11 로 높았다. 이는 탈색을 2 번 한 결과로 모발 시료 자체의 명도가 높은 결과로 사료된다. 이는 탈색모에 짙은 블루 실버로 도포 후 $\mathrm{L}^{*}$ 값이 상대적으로 낮은 명도를 나타냈다(Lee \& Kang, 2019)는 결과와 같 은 것을 알 수 있었다.
2) 시료 별 $a^{*}$ 측정

오트밀 오일 함량을 $0 \mathrm{~g}, 1 \mathrm{~g}, 2 \mathrm{~g}, 3 \mathrm{~g}$ 다르게 하여 제조한 모 질 개선 제형제로 시료 별 도포 후 모발 표면 색상 분석 결과 $\mathrm{a}^{*}$ 값은 Table 4와 같다.

오트밀 오일을 함유한 개선 제형제로 도포한 후의 대조군과 실험 군의 $a^{*}$ 값 결과는 대조군 인 건강모보다는 실험군 모두가 높게 나 타났다. 이 결과는 L'값의 결과와 같은 것을 알 수 있었다. 대조군 인 $0 \mathrm{~g}$ 함유한 것보다 실험군 7레벨에서 $1 \mathrm{~g}, 2 \mathrm{~g}, 3 \mathrm{~g}$ 함유한 시료 의 $\mathrm{a}^{*}$ 값은 오트밀 함량이 높을 수록 감소함을 알 수 있었다. 이는 오 트밀 오일이 모발 표면 등에 흡착이 된 결과로 사료된다. 7레벨에서 $1 \mathrm{~g}$ 과 $2 \mathrm{~g}$ 의 $\mathrm{a}^{*}$ 값 차이는 0.22 로 차이가 있음을 알 수 있었다. 오트 밀 오일 $3 \mathrm{~g}$ 을 도포한 7레벨과 9 레벨의 실험군의 $\mathrm{a}^{*}$ 값 차이는 9 레 벨의 a*값이 9.68 로 낮음을 알 수 있었다. 이는 탈색을 2 번 한 결과 로 모발 시료 적색 톤의 감소로 인한 결과로 사료된다. 이는 탈색이 강하게 거듭 될수록 적색 정도가 점차적으로 감소된다(Kim et al., 2006)는 결과와 같은 것을 알 수 있었다.

\section{3) 시료 별 $b^{*}$ 측정}

오트밀 오일 함량을 $0 \mathrm{~g}, 1 \mathrm{~g}, 2 \mathrm{~g}, 3 \mathrm{~g}$ 다르게 하여 제조한 모 질 개선 제형제로 시료 별 도포 후 모발 표면 색상 분석 결과 $b^{*}$ 값은 Table 5 와 같다.

오트밀 오일을 함유한 개선 제형제로 도포한 후의 대조군과 실험 군의 $b^{*}$ 값 결과는 대조군 인 건강모보다는 실험군 모두가 높게 나타 났다. 이 결과는 L'값의 결과와 같은 것을 알 수 있었다. 대조군 인 $0 \mathrm{~g}$ 함유한 것보다 실험군 7레벨에서 $1 \mathrm{~g}, 2 \mathrm{~g}, 3 \mathrm{~g}$ 함유한 시료의 $\mathrm{b}^{*}$ 값은 오트밀 함량이 높을수록 증가 함을 알 수 있었다. 이는 오트 밀 오일이 모발 표면 등에 흡착이 된 결과로 사료된다. 7레벨에서 1 $\mathrm{g}$ 과 $2 \mathrm{~g}$ 의 b*값 차이는 0.26 으로 차이가 있음을 알 수 있었다. 오트 밀 오일 $3 \mathrm{~g}$ 을 도포한 7레벨과 9 레벨의 실험군의 $\mathrm{b}^{*}$ 값 차이는 9 레벨

Table 3. Brightness $L^{*}$ value

\begin{tabular}{lcccccc}
\hline Sample & Virgin hair & 7 level Og & 7 level $1 g$ & 7 level $2 g$ & 7 level 3g & 9 level $3 g$ \\
$L^{*}$ value & 13.09 & 37.49 & 36.00 & 34.75 & 33.42 & 59.53 \\
\hline
\end{tabular}

Table 4. $a^{*}$ value

\begin{tabular}{lcccccc}
\hline Sample & Virgin hair & 7 level Og & 7 level $1 g$ & 7 level $2 g$ & 7 level 3g & 9 level 3g \\
\hline$a^{*}$ value & -8.70 & 16.62 & 16.40 & 15.70 & 15.40 & 5.72 \\
\hline
\end{tabular}

Table 5. $b^{*}$ value

\begin{tabular}{lcccccc}
\hline Sample & Virgin hair & 7 level 0g & 7 level 1g & 7 level 2g & 7 level 3g & 9 level 3g \\
\hline $\mathrm{b}^{*}$ value & -1.39 & 38.34 & 40.05 & 40.31 & 44.75 & 26.01 \\
\hline Table 6. Pigment loss & & & & & & (Unit: NTU) \\
\hline Sample (9 level 3 g) & 1 day & & 2 day & 3 day & 4 day \\
Pigment loss value & 16.68 & 6.85 & 1.31 & 0 \\
\hline
\end{tabular}


의 b*값이 18.74 로 낮음을 알 수 있었다. 이는 탈색을 2 번 한 결과로 모발 시료 황색 톤의 증가로 인한 결과로 사료된다.

\section{2. 시료 별의 물 빠짐 측정}

오트밀 오일로 도포한 시료의 물 빠짐 측정 결과는 Table 6과 같 다. 물 빠짐 측정을 위해서 함량을 가장 많이 첨가하고 명도가 높은 9 레벨의 시료로 물 빠짐 측정을 하였다. 이는 9 레벨의 모발 손상이 7 레벨보다 손상이 심하여 물 빠짐 역시 많을 것으로 판단하였기 때 문이다. 측정결과 1 일차에는 가장 많이 $16.68 \mathrm{NTU}$ 가 빠졌고, 2 일 차에는 $6.85 \mathrm{NTU}, 3$ 일차에는 $1.31 \mathrm{NTU}$ 이고, 4 일차부터 더 이상의 물 빠짐이 없었다. 오트밀 오일이 조금의 색을 가지고 있는 것으로 사료된다. 1-3일차까지 물 빠짐이 일어난 이유는 모발의 손상으로 인한 색의 유실(Kim \& Yoo, 2019)의 결과 인 것으로 사료된다.

\section{3. 시료 별의 인장강도 측정}

오트밀 오일 함량을 $0 \mathrm{~g}, 1 \mathrm{~g}, 2 \mathrm{~g}, 3 \mathrm{~g}$ 다르게 하여 제조한 모질 개선 제형제로 시료 별 도포 후 인장강도 결과는 Table 7과 같다.

오트밀 오일을 함유한 개선 제형제로 도포한 후의 대조군과 실험 군의 인장강도 측정 결과

대조군 인 건강모보다는 실험군 모두가 감소하였다. 이는 탈색으 로 인한 모발 손상의 결과인 것으로 사료되며 명도가 상승함에 따라 인장강도, 신장률이 감소하는 경향을 보인다(Lim \& Park, 2019)는 선행 연구 결과와 비슷한 결과임을 알 수 있었다. 대조군 인 $0 \mathrm{~g}$ 함 유한 것보다 실험군 7레벨에서 $1 \mathrm{~g}, 2 \mathrm{~g}, 3 \mathrm{~g}$ 함유한 시료의 인장강 도 값은 오트밀 함량이 높을수록 인장강도 값은 증가 함을 알 수 있 었다. 이는 오트밀 오일이 모발 개선에 효과가 있는 것으로 사료된 다. 7레벨에서 $2 \mathrm{~g}$ 과 $3 \mathrm{~g}$ 의 인장강도 결과는 차이는 0.01 로 큰 차이 는 없는 것을 알 수 있었다. 오트밀 오일 $3 \mathrm{~g}$ 을 도포한 7레벨과 9 레 벨의 실험군의 인장강도 결과 차이는 9 레벨의 인장강도 값이 0.10 으로 낮음을 알 수 있었다. 이는 탈색을 2 번 한 결과로 모발 손상에 의한 것으로 이는 탈색에 의해 인장강도가 감소한다(Lee \& Chang, 2008)는 결과와 같은 모발 손상에 의한 것으로 나타났다.

\section{4. 시료 별의 메틸렌블루를 이용한 흡광도 측정 결과}

오트밀 오일 함량을 $0 \mathrm{~g}, 1 \mathrm{~g}, 2 \mathrm{~g}, 3 \mathrm{~g}$ 다르게 하여 제조한 모 질 개선 제형제로 시료 별 도포 후 메틸렌블루의 흡광도 측정결과는 Table 8과 같다. 흡광도의 정확한 측정 결과를 위해 총 3 회 측정하 여 측정값의 평균값을 구했다.

오트밀 오일을 함유한 개선 제형제로 도포한 후의 대조군과 실험 군의 흡광도 측정 결과

대조군 인 건강모보다는 실험군 모두가 증가하였다. 이는 탈색으 로 인한 모발 손상의 결과인 것으로 흡광도가 높을수록 모표피의 다 공성 정도가 많아서 손상도가 높다(Lim, 2018)는 결과와 같은 것임 을 알 수 있었다. 대조군 인 $0 \mathrm{~g}$ 함유한 것보다 실험군 7레벨에서 1 $\mathrm{g}, 2 \mathrm{~g}, 3 \mathrm{~g}$ 함유한 시료의 흡광도 값은 오트밀 함량이 높을 수록 감 소 함을 알 수 있었다. 이는 오트밀 오일이 모표피, 모피질에 흡착, 흡수 된 결과로 모발 개선 효과가 있는 것을 알 수 있었다. 7레벨에 서 $1 \mathrm{~g}$ 과 $2 \mathrm{~g}$ 의 흡광도 결과 차이가 0.008 로 차이가 있음을 알 수 있었다. 오트밀 오일 $3 \mathrm{~g}$ 을 도포한 7레벨과 9 레벨의 실험군의 흡광 도 결과 차이는 9 레벨의 값이 0.173 으로 높음을 알 수 있었다. 이는 9 레벨의 실험군이 7 레벨의 실험군 보다 손상이 더 심한 결과로 이 는 화학 시술 후 methylene blue의 흡광도가 높게 나타나는 것은 시 료모발의 모표피와 모피질의 단백질이 소실되거나 변형되어 보다 많은 양의 methylene blue가 흡착된 후 탈 밀착되었기 때문(Oh \& Choe, 2012)이라는 결과로 사료된다.

\section{5. 시료 별의 광택 측정 결과}

오트밀 오일 함량을 $0 \mathrm{~g}, 1 \mathrm{~g}, 2 \mathrm{~g}, 3 \mathrm{~g}$ 다르게 하여 제조한 모질 개선 제형제로 시료 별 도포 후 측정결과는 Table 9 와 같다.

오트밀 오일을 함유한 개선 제형제로 도포한 후의 대조군과 실험 군의 광택 측정 결과 대조군 인 건강모보다는 실험군 모두가 증가하 였다. 이는 탈색으로 인한 시료 명도가 높아진 결과로 사료된다. 대 조군 인 $0 \mathrm{~g}$ 함유한 것보다 실험군 7레벨에서 $1 \mathrm{~g}, 2 \mathrm{~g}, 3 \mathrm{~g}$ 함유한 시료의 광택 값은 오트밀 함량이 높을 수록 그 차이의 폭은 미비하 게 감소하는 경향을 보였다. 이는 오트밀 오일의 흡착에 의한 것으 로 사료된다. 7 레벨에서 $1 \mathrm{~g}$ 과 $2 \mathrm{~g}$ 의 광택 측정 결과 차이가 없는 것

Table 7. Tensile strength value

(Unit: $\mathrm{kgf} / \mathrm{mm}^{2}$ )

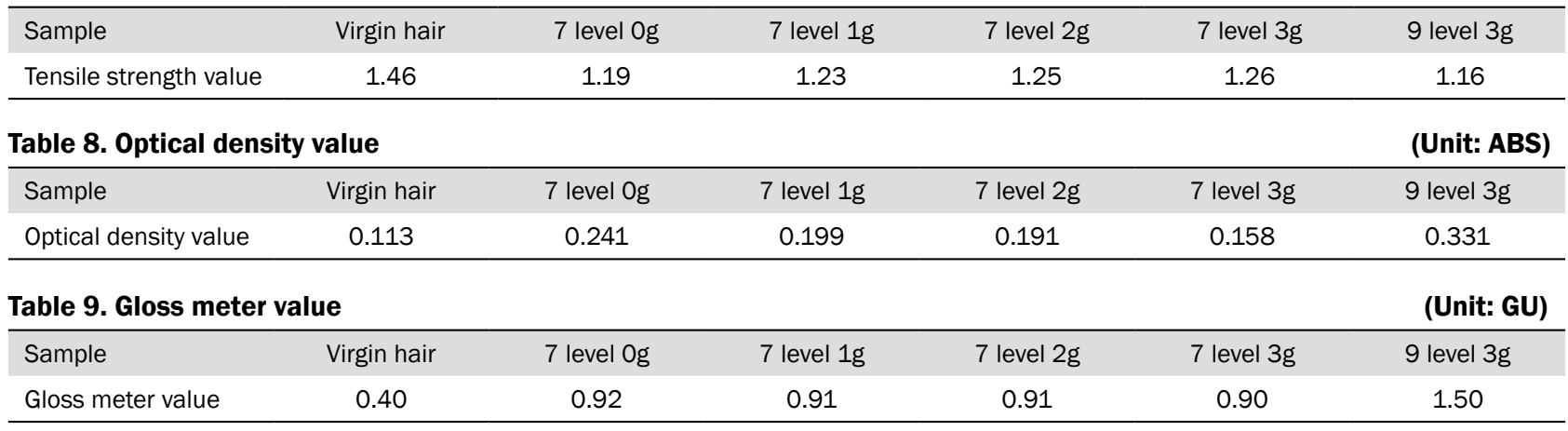


을 알 수 있었다. 오트밀 오일 $3 \mathrm{~g}$ 을 도포한 7레벨과 9 레벨의 실험군 의 광택 측정 결과 차이는 9 레벨의 값이 0.60 으로 높음을 알 수 있 었다. 이는 오일, 왁스 겔의 광택도는 오일 함량에 비례한다는(Choi et al., 2010)의 결과와 반대의 결과로 나타났다. 이는 오일이 모발 의 광택을 저해 할 수도 있다는 것을 알 수 있었다.

\section{Conclusion}

본 연구는 손상된 모발의 개선 정도를 알기 위해 오트밀 오일 성 분으로 제조한 조형제로 손상 된 모발에 도포 후 대조군과 실험군을 비교 분석 연구하였다. 모질 개선 효과를 알 기 위해 오트밀 오일을 $0 \mathrm{~g}, 1 \mathrm{~g}, 2 \mathrm{~g}, 3 \mathrm{~g}$ 으로 함량을 다르게 하여 모질 개선 제형제를 제 조하였다. 시료 별로 제조한 모질 개선 제형제를 도포 후 열처리 10 $\min$ 과 자연방치를 $20 \mathrm{~min}$ 하였다. 방치 한 후 플레인 린스 하여 모 발을 자연 건조하였다. 건조한 시료인 대조군과 실험군의 모발 표면 색상 변화를 분석하기 위해 $\mathrm{L}^{*}, \mathrm{a}^{*}, \mathrm{~b}^{*}$ 값, 오일 도포에 의한 시료의 물 빠짐 값을 비교 분석하였고, 모질의 개선 정도를 알기 위해 인장 강도, 메틸렌블루를 이용한 흡광도, 광태 측정을 하였다. 그 결과 다 음과 같은 결론을 얻었다.

첫째, 오트밀 오일을 함유한 개선 제형제로 도포한 후의 대조군과 실험군의 L*값 결과는 대조군 인 건강모보다 실험군 모두가 높은 것 으로 나타났다. 또한 대조군 인 $0 \mathrm{~g}$ 함유한 것보다 실험군 7레벨에 서 $1 \mathrm{~g}, 2 \mathrm{~g}, 3 \mathrm{~g}$ 함유한 시료의 L*값은 오트밀 함량이 높을수록 감 소함을 알 수 있었다. 이는 오트밀 오일이 모발 표면 등에 흡착이 된 결과로 사료된다. $a^{*}$ 값 결과는 대조군 인 건강모보다 실험군 모두가 높게 나타났다. 또한 대조군 인 $0 \mathrm{~g}$ 함유한 것보다 실험군 7레벨에 서 $1 \mathrm{~g}, 2 \mathrm{~g}, 3 \mathrm{~g}$ 함유한 시료의 $\mathrm{a}$ *값은 오트밀 함량이 높을 수록 감 소함을 알 수 있었다. $b{ }^{*}$ 값 결과는 대조군 인 건강모보다 실험군 모 두가 높게 나타났다. 대조군 인 $0 \mathrm{~g}$ 함유한 것보다 실험군 7레벨에 서 $1 \mathrm{~g}, 2 \mathrm{~g}, 3 \mathrm{~g}$ 함유한 시료의 $\mathrm{b}^{\star}$ 값은 오트밀 함량이 높을수록 증 가 함을 알 수 있었다.

둘째, 오트밀 오일의 물 빠짐을 알기 위한 측정 결과로는 1 일차에 는 가장 많이 $16.68 \mathrm{NTU}$ 가 빠졌고, 2 일차에는 $6.85 \mathrm{NTU}, 3$ 일차에 는 $1.31 \mathrm{NTU}$ 이고 4 일차부터는 더 이상의 물 빠짐이 없었다. 오트밀 오일이 조금의 색을 가지고 있는 것으로 사료된다.

셋째, 모질의 개선 정도를 알기 위한 대조군과 실험군의 인장강도 측정 결과 대조군 인 건강모보다는 실험군 모두가 감소하였다. 대조 군 인 $0 \mathrm{~g}$ 함유한 것보다 실험군 7레벨에서 $1 \mathrm{~g}, 2 \mathrm{~g}, 3 \mathrm{~g}$ 함유한 시 료의 인장강도 값은 오트밀 함량이 높을 수록 인장강도 값은 증가 함을 알 수 있었다. 이는 오트밀 오일이 모발 개선에 효과가 있는 것 으로 사료된다.

넷째, 모질의 개선 정도를 알기 위한 대조군과 실험군의 메틸렌블
루를 이용한 흡광도 측정 결과 대조군 인 건강모보다는 실험군 모두 가 증가하였다. 대조군 인 $0 \mathrm{~g}$ 함유한 것보다 실험군 7 레벨에서 $1 \mathrm{~g}$, $2 \mathrm{~g}, 3 \mathrm{~g}$ 함유한 시료의 흡광도 값은 오트밀 함량이 높을 수록 감소 함을 알 수 있었다. 이는 오트밀 오일이 모표피, 모피질에 흡착, 흡 수 된 결과로 모발 개선 효과가 있는 것을 알 수 있었다.

다섯째, 모질의 개선 정도를 알기 위한 대조군과 실험군의 광택 측정 결과 대조군 인 건강모보다는 실험군 모두가 증가하였다. 대조 군 인 $0 \mathrm{~g}$ 함유한 것보다 실험군 7레벨에서 $1 \mathrm{~g}, 2 \mathrm{~g}, 3 \mathrm{~g}$ 함유한 시 료의 광택 값은 오트밀 오일 함량이 높을 수록 그 차이의 폭은 미비 하게 감소하는 경향을 보였다. 이는 오트밀 오일의 흡착에 의한 것 으로 사료된다.

이와 같은 결과로 천연 오트밀 오일을 함유한 모질 개선 제형제가 손상 모발에 모질 개선효과가 있는지 연구한 결과 모질 개선 효과가 있는 것을 알 수 있었다. 모질 개선 제형제로 천연 오일에 대한 연구 가 이루어지고 있지만 다양한 오일류에 대한 연구는 미비한 실정이 다. 차후 식물성, 동물성 오일 등 다양한 종류의 오일류 개발이 더 필요하고, 오일 성분의 특성에 따른 모발 개선 효과 및 지속성 등에 관한 연구가 필요하다.

\section{Author's contribution}

JSK designed all experimental investigations, collected oatmeal oil data and wrote the manuscript.

\section{Author details}

Ju-Sub Kim (Professor), Department of Beauty Design, Sangji University, 84 Sangjidae-gil, Wonju-si, Gangwondo 26339, Korea.

\section{References}

Bang SK, Son EJ, Kim HJ, Park S. Quality characteristics and glycemic index of oatmeal cookies made with artificial sweeteners. Journal of the Korean Society of Food Science and Nutrition, 42: 877-884, 2013.

Choi EJ, Park SH. The effects of water wrapping procedure at permanent wave upon wave efficiency. Asian Journal of Beauty and Cosmetology, 24: 269-278, 2010.

Choi KH, Son HH, Lee SM. The effect of glossiness and lattice structure of wax matrixes on using n-parrafin and branched wax. Journal of the Society of Cosmetic Scientists of Korea, 36: 99-103, 2010.

Choi YK, Lee SH. A morphological and chemical variation of 
hair treated by deep ocean water. Journal of the Korean Society of Urban Environment, 35: 101-108, 2015.

Hwang JU, Yang YH, Choe TB. Physiological characteristics of germinated oat (Avena sativa) extract as raw material for cosmetics. Asian Journal of Beauty and Cosmetology, 18: 137-148, 2020.

Kang EN. Effects of hair treatment for bleaching on hair color. Journal of the Korean Society of Beauty and Arts, 51: 5159, 2015.

Kim HE, Kim MH, Kim YS. Taste compounds and quality characteristics of doenjang (soybean paste) added with oat powder. Journal of Agricultural \& Life Science, 47: 2431, 2016.

Kim JS, Kim CS, Kim YJ, Yoo SE. Hair science. Hoonminsa, Seoul, p76-77, 2010.

Kim JS, Yoo SE. Natural dyeing materials from Opuntia humifusa for hair. Asian Journal of Beauty and Cosmetology, 63: 129-138, 2019.

Kim KS, Jeon DW, Ha BJ. Studies on the surface color and tensile property of hair according to bleaching treatment. Fashion Business, 10: 94-105, 2006.

Kim MS, Han JS. A study of effect of natural extract on improvement of hair damage. Journal of the Korean Society of Beauty and Arts, 44: 249-262, 2013.

Lee GY, Chang BS. Study on the tensile strength of bleached hair. Korean Journal of Microscopy, 38: 251-257, 2008.

Lee JS, Kang SM. The effects of lugworms autolysate on the blue silver dyeing of bleached hair. Journal of the Korean Society of Cosmetology, 25: 772-785, 2019.

Lee YJ, Kim JS, Kim KM, Choi SY, Kim GC. Nutritional components and physicochemical properties of hulled and naked oat flours according to particle sizes. Journal of the Korean Society of Food Science and Nutrition, 45: 1293-1301, 2016.

Lim DJ. Improvement effects of hair texture by using sodium bromate oxidizing agent. The Korean Society of Science \& Art, 35: 391-400, 2018.

Lim SN, Park JS. Study on the tensile strength of virgin hair by high-density oxidative dye application. Journal of Digital Convergence, 17: 447-452, 2019.

Min MJ, Choi MH, Kim GC, Shin HJ. Damage prevention effect of green tea seed oil on colored and decolored hair. Korean Society for Biotechnology and Bioengineering Journal, 28: 287-294, 2013.

Oh MS, Choe TB. Determination of hair damage index using methylene blue staining method. Journal of The Korean Society of Cosmetology, 18: 531-537, 2012.

Park SH, Lee MS. The effect of scalp manual technic using aroma oils on scalp and hair condition. Journal of Investigative Cosmetology, 18:263-269, 2012.

Park SY. The study on safety of olive oil production ozonized of hair and skin improvement. Journal of Oil \& Applied Science, 32: 583-587, 2015. 


\section{국문초록}

\section{오트밀 오일의 모질 개선 효과}

김주섭

상지대학교 뷰티디자인학과, 강원도 원주시, 한국

목적: 본 연구는 오트밀 오일로 모질 개선 제형제를 제조하여 손상된 모발에 도포하여 모질 개선 효과를 알아보고자 하였다. 방법: 오트밀 오일 함량을 $0 \mathrm{~g}, 1 \mathrm{~g}, 2 \mathrm{~g}, 3 \mathrm{~g}$ 으로 다르게 하여 모질 개선 제형제를 제조하였다. 제조한 개선 제형제로 탈색한 시료 모발에 도포 후 열처리와 자연방치를 한 후에 대조군과 실험군을 측정하여 비교 분석하였다. 오일에 의한 표면 색상 변화를 알기 위해 색차 계를 이용하여 $\mathrm{L}^{*}, \mathrm{a}^{*}, \mathrm{~b}^{*}$ 값과 물 빠짐 정도를 측정하였다. 또한 모질 개선 효과를 알기 위해 인장강도, 메틸렌블루를 이용한 흡광 도, 광택을 측정하였다. 결과: $\mathrm{L}^{*}, \mathrm{a}^{*}, \mathrm{~b}^{*}$ 측정 결과는 $\mathrm{L}^{*}$ 값은 대조군과 실험군의 $\mathrm{L}^{*}$ 값 결과는 대조군 인 건강모보다는 실험군 모두 가 높은 것으로 나타났다. 또한 실험군 7레벨에서의 $\mathrm{L}^{*}$ 값은 오트밀 함량이 높을수록 감소함을 알 수 있었다. $\mathrm{a}^{\star}$ 값은 건강모보다는 실험군 모두가 높게 나타났다. 또한 실험군 7레벨에서의 $\mathrm{a}^{*}$ 값은 오트밀 함량이 높을 수록 감소함을 알 수 있었다. $\mathrm{b}^{*}$ 값은 건강모보 다는 실험군 모두가 높게 나타났다. 실험군 7레벨에서의 $b^{*}$ 값은 오트밀 함량이 높을수록 증가 함을 알 수 있었다. 물 빠짐 측정결과 는 1 일차에는 가장 많이 $16.68 \mathrm{NTU}$ 가 빠졌고, 4 일차부터는 더 이상의 물 빠짐이 없었다. 인장강도 측정결과 건강모보다는 실험군 의 인장강도는 감소하였다. 7 레벨에서의 인장강도는 오트밀 오일 함량이 높을수록 증가하였다. 광택 측정 결과는 건강모보다는 실 험군의 광택 값이 증가하였으나, 7 레벨에서의 광택 값은 함량이 증가할수록 미미하게 감소하였다. 결론: 오트밀 오일이 손상된 모 발에 모질 개선 효과가 있다는 것을 알 수 있었다. 차후 오일 성분의 특성에 따른 모발 개선 효과 및 지속성 등에 관한 연구가 필요 하다.

핵심어: 오트밀 오일, 모발, 개선, 모질, 손상

\section{참고문헌}

강은란. 모발탈색 시 트리트먼트 처리에 따른 색차의 변화 연구. 한국인체미용예술학회지, 51: 51-59, 2015.

김경선, 전동원, 하병조. 모발(毛髮)의 탈색정도(脫色程度)에 따른 인장특성(引長特性)과 표면색 변화 연구(表面色 變化 研 究). 패션비즈니스, 10: 94-105, 2006.

김민선, 한진섭. 천연추출물의 손상모발 개선효과에 관한 연구. 한국인체미용예술학회지, $44: 249-262,2013$. 김주섭, 김찬수, 김유정, 유세은. 모발과학. 훈민사, 서울, $\mathrm{p} 76-77,2010$.

김형은, 김민희, 김용석. 귀리분말을 첨가한 된장의 맛 성분과 특성. 농업생명과학연구, 47: 24-31, 2016. 김주섭, 유세은. 백련초의 모발에 대한 천연 염색 원료 연구. 아시안뷰티화장품학술지, 63: 129-138, 2019. 민명자, 최문희, 김귀철, 신현재. 녹차씨 오일이 염색 및 탈색된 모발의 재손상 및 탈색 방지에 미치는 영향. $K S B B$

Journal, 28: 287-294, 2013.

박선이. 모발 및 피부 개선의 오존화 올리브 오일 생산에 대한 안전성에 관한 연구. 한국유화학회지. 32: 583-587, 2015. 방성권, 손은정, 김효진, 박선민. 대체감미료를 첨가한 오트밀쿠키의 품질 특성 및 혈당에 미치는 영향. 한국식품영양과학 회지, 42: 877-884, 2013.

박수형, 이명숙. 아로마 오일을 이용한 두피수기요법이 두피와 모발 상태에 미치는 영향. 대한미용학회지, 18: 263-269, 2012.

이귀영, 장병수. 탈색모발의 인장강도에 관한 연구. 한국현미경학회지, 38: 251-257, 2008.

이유진, 김진숙, 김경미, 최송이, 김기창. 겉귀리 및 쌀 귀리분말의 입자크기별 영양성분 및 이화학적 특성. 한국식품영양 과학회지, 45: 1293-1301, 2016. 
이정섭, 강상모. 갯지렁이 자가분해물이 탈색모발의 블루실버 염색에 미치는 영향. 한국미용학회지, 25: 772-785, 2019. 임대진. 브롬산나트륨 산화제 사용에 의한 모발 개선효과. 한국과학예술융합학회지, 35: 391-400, 2018.

임순녀, 박장순. 버진 헤어(Virgin hair)의 고명도(高明渡) 산화염모제 시술에 따른 모발 인장강도 연구. 디지털융복합연 구, 17: 447-452, 2019.

오명숙, 최태부. Methylene Blue 염색법을 이용한 모발손상지수의 결정. 한국미용학회지, 18: 531-537, 2012.

최기환, 손홍하, 이상민. 직쇄 파라핀 왁스와 분자 왁스 사용에 따른 오일-왁스 켈에 미치는 왁스 구조와 광택에 미치는 영 향 연구. 대한화장품학회지, 36: 99-103, 2010.

최은정, 박수향. 퍼머넌트웨이브시 water wrapping 시술이 웨이브효율성에 미치는 영향. 아시안뷰티화장품학술지, 24: 269-278, 2010.

최윤경, 이상혁. 해양 심충수로 모발 처리시 형태학적 및 화학적 변화. 한국도시환경학회지, 35: 101-108, 2015. 황지우, 양영헌, 최태부. 화장품 소재로서 발아 귀리 추출물의 생리활성 특성. 아시안뷰티화장품학술지, 18: 137-148, 2020. 


\section{中文摘要}

\section{燕麦油对改善头发质地的作用}

金周焂

尚志大学美容学科, 江原道原州市, 韩国

目的: 研究旨在评估燕麦油对改善头发质地的作用。因此, 开发了燕麦油剂, 并将其用于受损的头发。方法: 用 不同量的燕麦油（0、1、2和3 g) 生产头发质地改善剂。将药剂涂在漂白的头发上后, 将其热处理并置于自然 状态。对实验组和对照组进行评估和比较。结果：实验组的 $L^{*}$ 值高于对照组。实验组的 $a^{*}$ 值高于对照组。实验组 的 $b^{\star}$ 值高于对照组。在第1天观察到褪色高达16.68 NTU, 但在第4天没有观察到。实验组的头发抗张强度低于 对照组。在7级中, 抗张强度随着燕麦油含量的增加而增加。此外, 实验组的光泽度高于对照组。但是, 在7级 时, 随着燕麦油含量的增加, 光泽度值略有下降。结论: 这项研究表明燕麦油可以改善受损发质。但是, 关于效 果的进一步研究。

关键词: 燕麦油, 头发, 改善, 头发质地，损伤 